\title{
Production of Inflammatory Mediators by Monocytes in Patients with Obstructive Sleep Apnea Syndrome
}

\author{
Shinji Tamaki, Motoo Yamauchi, Atsuhiko Fukuoka, Kiyoshi Makinodan, Noriko Koyama, \\ Koichi Tomoda, Masanori Yoshikawa and Hiroshi Kimura
}

\begin{abstract}
Background Obstructive sleep apnea syndrome (OSAS) is known to be a risk factor of cardiovascular events. However, the precise mechanism linking the two has not been fully elucidated.

Objective The aim of this study was to investigate the effect of hypoxic stress on the production of tumor necrosis factor (TNF)- $\alpha$, monocyte chemoattractant protein-1 (MCP-1), and matrix metalloproteinase-9 (MMP-9) by monocytes.

Methods Thirty-three OSAS patients and 13 healthy control subjects were enrolled. The OSAS patients were classified as mild-to-moderate (13) and severe (20). Venous blood samples were collected before and after sleep as well as after long-term nasal continuous positive airway pressure (CPAP) treatment for the purpose of isolation of monocytes. Peripheral blood monocytes were isolated using standard methods. Monocytes were cultured under lipopolysaccharide stimulation for 24 hours, and TNF- $\alpha$, MCP-1, and MMP-9 in the culture supernatants were determined by ELISA.

Results In severe patients, the TNF- $\alpha$ production by monocytes was significantly elevated as compared to that before sleep $(\mathrm{p}<0.01)$. In all OSAS patients, the TNF- $\alpha$ production after sleep was significantly correlated with AHI $(\mathrm{p}<0.01)$, ODI $(\mathrm{p}<0.01)$ and \% time in $\mathrm{SpO}_{2}<90 \%(\mathrm{p}<0.05)$, and inversely correlated with the lowest $\mathrm{SpO}_{2}(\mathrm{p}<0.01)$. The production of MCP-1 and MMP-9 by monocytes was significantly elevated compared to that before sleep in severe patients $(\mathrm{p}<0.05)$. The production of these mediators by monocytes was significantly decreased after long-term nasal CPAP treatment $(\mathrm{p}<0.05)$.

Conclusion These results indicate that OSAS-induced hypoxic stress activates the production of inflammatory mediators by monocytes.
\end{abstract}

Key words: monocyte, atherosclerosis, tumor necrosis factor- $\alpha$, monocyte chemoattractant protein-1, matrix metalloproteinase-9, sleep apnea

(Inter Med 48: 1255-1262, 2009)

(DOI: 10.2169/internalmedicine.48.2366)

\section{Introduction}

Obstructive sleep apnea syndrome (OSAS) is characterized by recurrent episodes of oxygen desaturation during sleep, the development of daytime sleepiness, and deterioration in the quality of life. OSAS is recognized as a major health care problem and has recently received a fair amount of attention due to the well-documented high prevalence of cardiovascular disease sequelae, including the increased risk of myocardial infarction, hypertension, and stroke (1).
Cross-sectional and prospective studies have implicated OSAS as an important causal factor in the development of cardiovascular disease (2). Although it is postulated that OSAS-induced hypoxic stress may contribute to the etiology of cardiovascular events, the precise mechanisms have not been fully elucidated. One of the potential mechanisms is that OSAS-induced hypoxic stress modulates circulating pro-inflammatory mediators. Atherosclerosis is described as an inflammatory disease on the basis of atheromatous lesions having been established as active sites of inflammation and immune responses involving pro-inflammatory cytoki- 
nes, chemokines and adhesion molecules $(3,4)$. The view that chronic inflammation initiated by monocyte and lymphocyte adhesion to activated endothelial cells plays a central role in the pathogenesis of atherosclerosis is now widely accepted (5). Tumor necrosis factor (TNF)- $\alpha$, the proinflammatory cytokine, is recognized as a critical factor in the development of atherosclerosis. It has been demonstrated that circulating levels of TNF- $\alpha$ are predictive of cardiovascular events (6). Monocyte chemoattractant protein-1 (MCP1) is a member of the $\mathrm{C}-\mathrm{C}$ family of chemokines, which play an important role in monocyte recruitment (7). Growing evidence suggests that MCP-1 is important in the inflammatory process associated with the pathogenesis and progression of atherosclerosis (8), acute coronary syndrome, and congestive heart failure (9). Matrix metalloproteinases (MMPs) are a family of enzymes that degrade the extracellular matrix (10) and play an important role in cardiac and vascular remodeling $(11,12)$. MMP-9 may be involved in long-term remodeling processes (13) and plaque instability (14). Macrophages and smooth muscle cells of human atherosclerotic plaques have been shown to synthesize MMP-9 (15).

It has already been demonstrated that plasma levels of TNF- $\alpha$ are elevated in patients with $\operatorname{OSAS}(16,17)$ and a recent study has shown that the production of TNF- $\alpha$ by monocytes is elevated in patients with OSAS (18). In addition, the serum levels of MCP-1 are elevated in patients with OSAS $(19,20)$, as are the serum levels and activity of MMP-9 (21). These changes have then been shown to be attenuated after therapy with nasal continuous positive airway pressure (CPAP) (21). However, these studies did not investigate the changes of inflammatory mediators resulting from nocturnal hypoxic stress in OSAS.

The aim of the present study was to investigate the effect of nocturnal hypoxic stress on the production of TNF- $\alpha$, MCP-1 and MMP-9 by peripheral blood monocytes. To evaluate the influence of hypoxic stress, we compared these changes before and after sleep. We also examined the effects of long-term CPAP treatment on the production of TNF- $\alpha$, MCP-1 and MMP-9.

\section{Methods}

\section{Subjects}

Thirty-three OSAS patients (30 males and 3 females) and 13 healthy control subjects were enrolled. OSAS patients were classified according to severity, i.e., 13 mild-tomoderate patients (apnea-hypopnea index, AHI<30) and 20 severe patients $(\mathrm{AHI} \geq 30)$ as determined by full standard polysomnography (PSG). In control subjects it was confirmed that AHI was less than 10 by PSG. Subjects who were taking medications for hypertension, hyperlipidemia, cardiovascular diseases, and diabetes mellitus were excluded from this study. The study was approved by the Institutional Review Board of Nara Medical University, and informed consent was obtained from all participants.

\section{Sleep study}

PSG was performed using a computerized polysomnogram system (Alice 4; Respironics; Pittsburgh, PA, USA) for 2 consecutive nights. Apnea was defined as cessation of airflow or a decrease in airflow to less than $20 \%$ of baseline for $>10 \mathrm{~s}$, and hypopnea was defined as a discernible decrease in airflow to less than $50 \%$ of baseline associated with a fall in oxygen saturation of $\geq 4 \%$ from baseline. Desaturation during sleep was assessed in terms of oxygen desaturation index of more than $3 \%$ desaturation (ODI), time in relation to total sleep time with $\mathrm{SpO}_{2}<90 \%$ (\% time in $\mathrm{SpO}_{2}<90 \%$ ), and lowest $\mathrm{SpO}_{2}$. In the night following the diagnosis of OSAS by PSG, patients underwent a second PSG by which apnea was mostly reduced or eliminated under nasal CPAP titration (REMstar Auto; Respironics).

\section{Isolation of peripheral blood monocytes}

Whole heparinized blood was collected from all patients and control subjects both before sleep, and again after sleep with PSG in the early morning (6:30 AM). Ten of these patients with OSAS also had blood samples taken at 3 months after long-term CPAP treatment (6:30 AM). Peripheral blood monocytes were isolated using standard methods (22).

\section{Determination of TNF- $\alpha$, MCP-1 and MMP-9 production by monocytes}

In both OSAS patients and control subjects, monocytes were cultured under lipopolysaccharide (LPS) stimulation for 24 hours. Two hundred $\mu \mathrm{l}$ of monocyte suspension set at $2.5 \times 10^{6}$ cells per $\mathrm{ml}$ was poured into each well of a 96-well TC plate (Corning 3799; Corning, Corning, NY). LPS (E. coli 055:B5 Calbiochem, San Diego, CA, USA) was added to the suspension to achieve a final concentration of $10 \mu \mathrm{g}$ / $\mathrm{ml}$. After the plate was cultured for 24 hours at $37^{\circ} \mathrm{C}$ under $5 \% \mathrm{CO}_{2}$, the culture supernatant was collected and stored at $-80^{\circ} \mathrm{C}$ until analysis.

TNF- $\alpha$, MCP-1 and MMP-9 concentrations in the culture supernatant were determined by enzyme-linked immunosorbent assay (ELISA). TNF- $\alpha$, MCP-1 and MMP-9 concentrations were measured using Human TNF- $\alpha$ ELISA kit, MCP-1 ELISA kit (R\&D Systems, Inc., Minneapolis, MN, USA), and Human MMP-9 ELISA kit (Amersham Pharmacia Biotech, UK Limited).

\section{Statistical analysis}

Statistical analysis was performed using Stat View version 5.0 (SAS Institute Inc, Cary, NC, USA). Changes within groups were analyzed by Wilcoxon signed-ranks test, and differences between two groups were analyzed by MannWhitney U test. Differences between three groups were analyzed by one-way analysis of variance followed by Scheffe's method. Correlations were analyzed by Pearson's correlation coefficient. Data were expressed as mean \pm SD. A probability value $<0.05$ was considered to indicate significance. 
Table 1. Characteristics and Anthropometric Data for Evaluating the Production Ability by Monocytes in OSAS Patients and Control Subjects

\begin{tabular}{|c|c|c|c|}
\hline & \multirow[t]{2}{*}{ Controls } & \multicolumn{2}{|c|}{ OSAS } \\
\hline & & $\begin{array}{l}\text { Mild-to-moderate } \\
(\mathrm{AHI}<\mathbf{3 0})\end{array}$ & $\begin{array}{c}\text { Severe } \\
(\mathrm{AHI}>=\mathbf{3 0})\end{array}$ \\
\hline n & 13 & 13 & 20 \\
\hline $\operatorname{Age~(yr)~}$ & $35.5 \pm 9.7^{*}$ & $56.1 \pm 8.7$ & $50.5 \pm 12.2$ \\
\hline Sex (male/female) & $12 / 1$ & $11 / 2$ & $19 / 1$ \\
\hline BMI $\left(\mathrm{kg} / \mathrm{m}^{2}\right)$ & $23.6 \pm 2.6$ & $24.6 \pm 2.7$ & $30.7 \pm 5.8$ \\
\hline AHI & $3.8 \pm 1.8$ & $18.3 \pm 4.9^{\S}$ & $60.4 \pm 19.2$ \\
\hline ODI & $5.5 \pm 2.0$ & $14.5 \pm 5.0$ & $51.7 \pm 18.7^{+}$ \\
\hline Lowest $\mathrm{SpO}_{2}(\%)$ & $89.4 \pm 4.0$ & $82.3 \pm 5.5^{5}$ & $68.2 \pm 8.5$ \\
\hline $\begin{array}{l}\% \text { Time in } \\
\mathrm{SpO}_{2}<90 \%(\%)\end{array}$ & $0.1 \pm 0.1$ & $10.9 \pm 12.2$ & $26.6 \pm 14.0$ \\
\hline
\end{tabular}

BMI, body mass index $\left(\mathrm{kg} / \mathrm{m}^{2}\right)$; AHI, Apnea-hypopnea index;

ODI, oxygen desaturation index more than $3 \%$ desaturation;

*; $p<0.01$ vs both OSAS groups $\quad t ; p<0.01$ vs mild-to-moderate OSAS and Controls

$\ddagger ;<0.001$ vs mild-to-moderate OSAS and Controls $\S ; \mathrm{p}<0.05$ vs Contorols

Controls

(ng/mL)

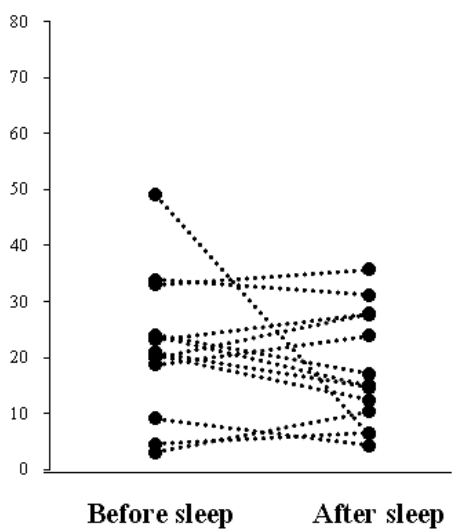

Mild-to-moderate OSAS

(ng/mL)

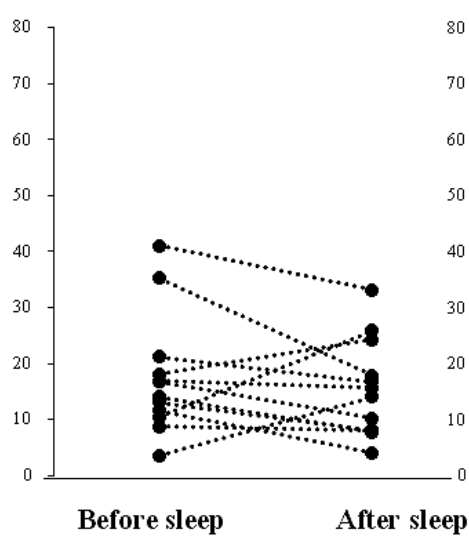

Severe OSAS

(ng/mL)

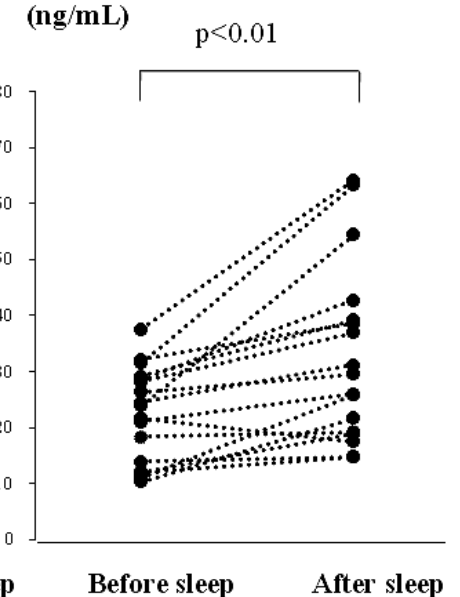

Figure 1. Production of TNF- $\alpha$ by monocytes extracted before and after sleep in mild-to-moderate $(\mathrm{AHI}<30)$ and severe $(\mathrm{AHI} \geq 30)$ OSAS and in control subjects. In severe patients, the TNF- $\alpha$ production after sleep was significantly elevated as compared to that before sleep $(\mathbf{p}<0.01)$.

\section{Result}

\section{Patient characteristics}

The characteristics of OSAS patients and control subjects are shown in Table 1. Control subjects were significantly younger than both patient groups. Body mass index (BMI) was significantly higher in severe patients than in mild-tomoderate patients and control subjects. AHI, ODI, lowest $\mathrm{SpO}_{2}$ and \% time in $\mathrm{SpO}_{2}<90 \%$ were significantly worse in severe patients compared to mild-to-moderate patients and control subjects. AHI and lowest $\mathrm{SpO}_{2}$ were significantly worse in mild-to-moderate patients than in control subjects.

\section{TNF- $\alpha$, MCP-1 and MMP-9 production by monocytes before treatment}

In control subjects and mild-to-moderate patients, there were no significant changes in the TNF- $\alpha$ production by monocytes before and after sleep (Fig. 1). On the contrary, in severe patients, the TNF- $\alpha$ production after sleep was significantly elevated as compared to that before sleep (26.6 \pm 22.2 to $32.9 \pm 15.9 \mathrm{ng} / \mathrm{mL}, \mathrm{p}<0.01)$.

The MCP-1 and MMP-9 productions in the early morning were significantly increased after sleep in severe patients $(28.4 \pm 14.3$ to $35.0 \pm 29.8 \mathrm{ng} / \mathrm{mL}$ in $\mathrm{MCP}-1$, and $1.93 \pm 2.4$ to $5.0 \pm 6.3 \mathrm{ng} / \mathrm{mL}$ in MMP-9, $\mathrm{p}<0.05)$. There were no significant changes in the production of MCP-1 and MMP-9 before and after sleep in the mild-to-moderate patients and control subjects (Figs. 2, 3). 


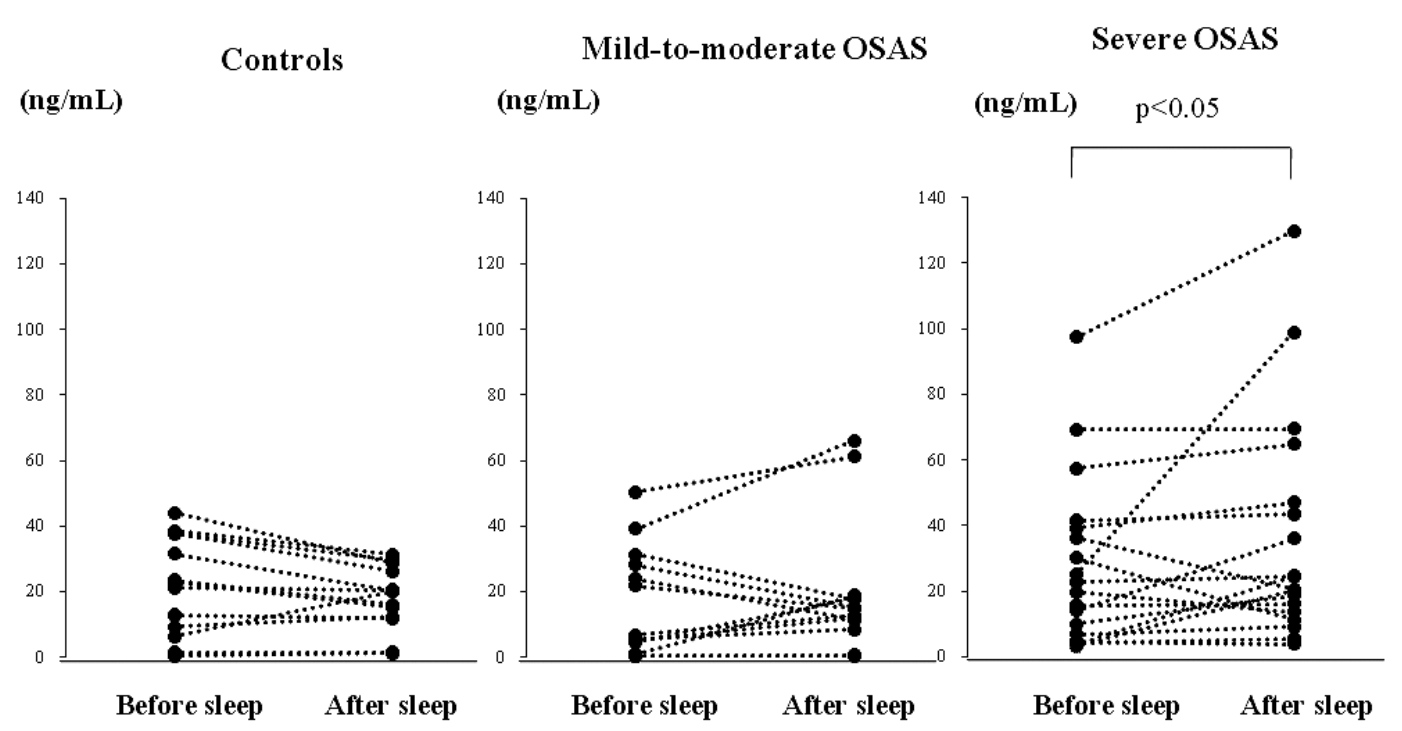

Figure 2. Production of MCP-1 by monocytes extracted before and after sleep in mild-to-moderate $(\mathrm{AHI}<30)$ and severe $(\mathrm{AHI} \geq 30)$ OSAS and in control subjects. In severe patients, the MCP-1 production after sleep was significantly elevated as compared to that before sleep $(p<0.05)$.

Controls

(ng/mL)

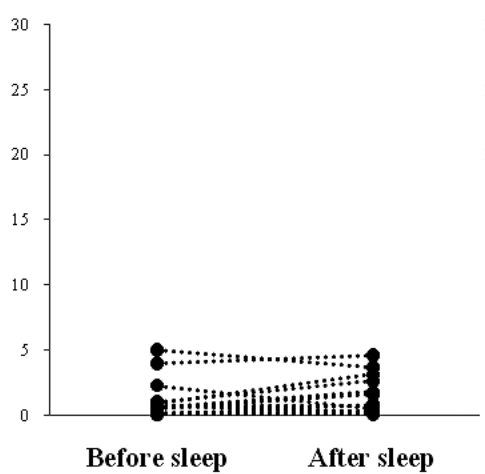

Mild-to-moderate OSAS

$(\mathbf{n g} / \mathbf{m L})$

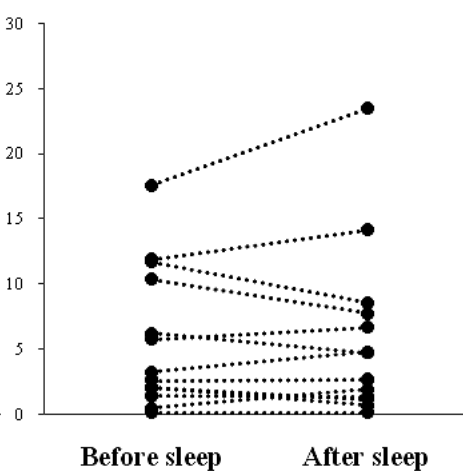

Severe OSAS

(ng/mL)

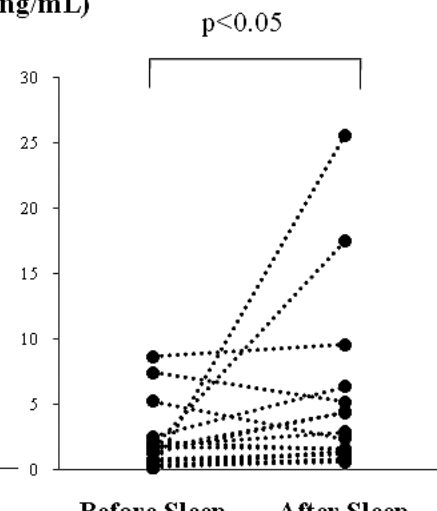

Figure 3. Production of MMP-9 by monocytes extracted before sleep and after sleep in mildmoderate $(\mathrm{AHI}<30)$ and severe $(\mathrm{AHI} \geq 30)$ OSAS and in control subjects. In severe patients, the MMP-9 production after sleep was significantly elevated as compared to that before sleep $(\mathbf{p}<0.05)$.

\section{Relationship between TNF- $\alpha$ production after sleep and PSG parameters and BMI}

In all OSAS patients, the TNF- $\alpha$ production after sleep was significantly correlated with AHI, ODI and \% time in $\mathrm{SpO}_{2}<90 \%$, and inversely correlated with the lowest $\mathrm{SpO}_{2}$ (Fig. 4). Moreover, TNF- $\alpha$ production was significantly correlated with BMI $(\mathrm{r}=0.481, \mathrm{p}<0.01)$ (data not shown).

\section{Long-term effect of CPAP on TNF- $\alpha, M C P-1$ and MMP-9 production by monocytes}

The effects of CPAP on the production of TNF- $\alpha$, MCP-1 and MMP-9 by monocytes in the early morning were investigated at 3 months after long-term CPAP treatment. There was no significant change of body weight in OSAS patients. A significant decrease in the production of TNF- $\alpha$, MCP- 1 and MMP-9 was observed after long-term CPAP treatment $(37.8 \pm 15.9$ to $18.4 \pm 12.4 \mathrm{ng} / \mathrm{mL}, 38.4 \pm 30.1$ to $11.9 \pm 7.8 \mathrm{ng} /$ $\mathrm{mL}$, and $7.89 \pm 10.4$ to $1.28 \pm 1.12 \mathrm{ng} / \mathrm{mL}, \mathrm{p}<0.05$, respectively) (Fig. 5).

\section{Evaluation after adjustment for age and BMI}

To eliminate the effects of body weight and age, we evaluated the production of TNF- $\alpha$, MCP-1, and MMP-9 by monocytes after sleep in the subgroups of OSAS and control subjects after adjustment for age and BMI as covariates. In severe patients, the production of TNF- $\alpha(30.2 \pm 6.9 \mathrm{ng} / \mathrm{mL})$ was significantly higher in OSAS patients than in mild-tomoderate patients $(22.7 \pm 4.1 \mathrm{ng} / \mathrm{mL}, \mathrm{p}<0.001)$ and control subjects $(17.3 \pm 4.4 \mathrm{ng} / \mathrm{mL}, \mathrm{p}<0.001)$ (Fig. 6). The production of TNF- $\alpha$ in mild-to-moderate patients was significantly higher than in control subjects $(\mathrm{p}<0.05)$. In severe patients, 

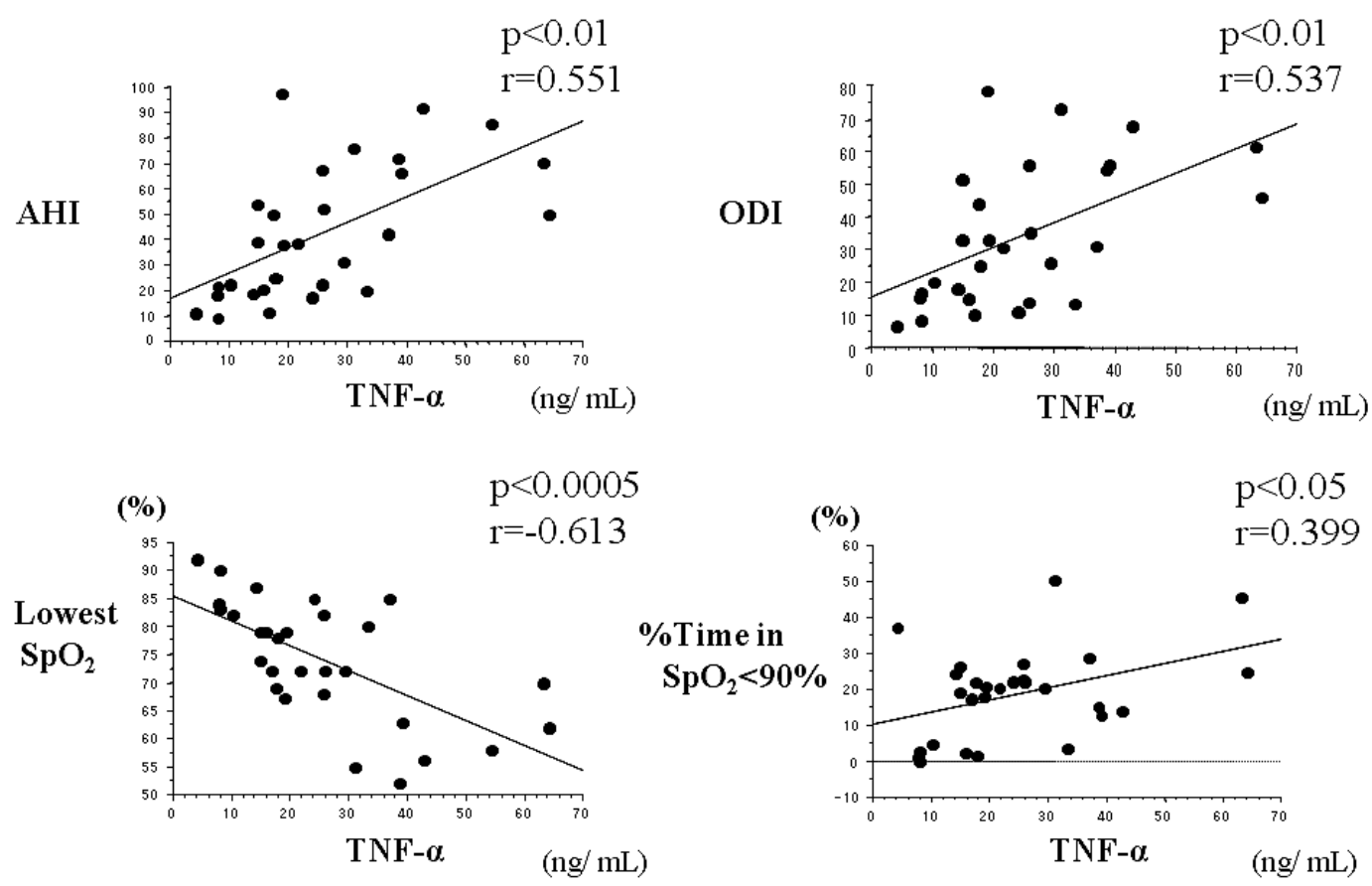

Figure 4. Relationships of sleep parameters and the production of TNF- $\alpha$ by monocytes extracted in the early morning. In all OSAS patients, the TNF- $\alpha$ production after sleep was significantly correlated with AHI $(r=0.551, p<0.01)$, ODI $(r=0.537, p<0.01)$ and \% time in $\mathrm{SpO}_{2}<90 \%$ $\mathrm{r}=0.399, \mathrm{p}<0.05)$, and inversely correlated with the lowest $\mathrm{SpO}_{2}(\mathrm{r}=-0.613, \mathrm{p}<0.0005)$.

TNF-a

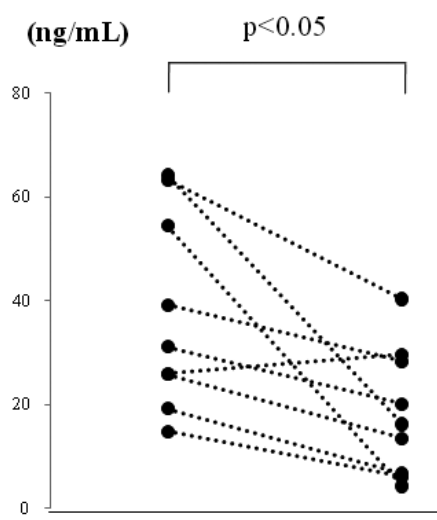

Before CPAP 3 months After CPAP
MCP-1

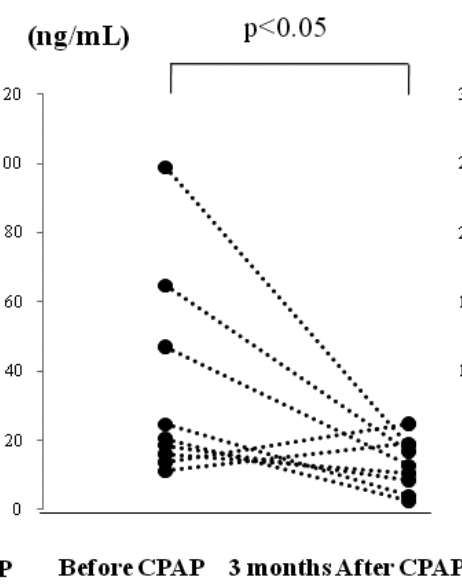

MMP-9

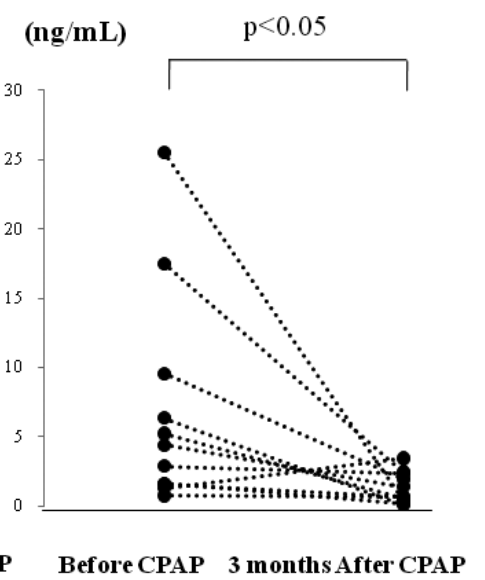

Figure 5. Effects of CPAP (3 month period) on the production of TNF- $\alpha$, MCP-1 and MMP-9 by monocytes extracted in the early morning. A significant decrease in the TNF- $\alpha$ production was observed after long-term CPAP treatment $(\mathbf{p}<\mathbf{0 . 0 5})$. The production of MCP-1 and MMP-9 was also significantly decreased after long-term CPAP $(\mathbf{p}<0.05)$.

the production of MCP-1 $(30.2 \pm 6.7 \mathrm{ng} / \mathrm{mL})$ was significantly higher than in mild-to-moderate patients $(24.5 \pm 2.0$ $\mathrm{ng} / \mathrm{mL}, \mathrm{p}<0.01)$ and control subjects $(22.6 \pm 2.8 \mathrm{ng} / \mathrm{mL}, \mathrm{p}<$ $0.01)$. In severe patients, the production of MMP-9 $(5.8 \pm 1.7$ $\mathrm{ng} / \mathrm{mL}$ ) was significantly higher than in control subjects $(1.5 \pm 1.8 \mathrm{ng} / \mathrm{mL}, \mathrm{p}<0.001)$. The production of MMP-9 in mild-to-moderate patients $(5.3 \pm 1.8 \mathrm{ng} / \mathrm{mL})$ was significantly higher than in control subjects $(\mathrm{p}<0.001)$. Otherwise, the production of these mediators before sleep did not indicate significant differences among the three groups.

\section{Discussion}

The present studies indicated that OSAS-induced hypoxic stress activates the production of inflammatory mediators by monocytes, and this phenomenon may contribute to the development of atherosclerosis. Therefore, it is suggested that CPAP treatment could play a role in the prevention of atherosclerosis in OSAS patients. 

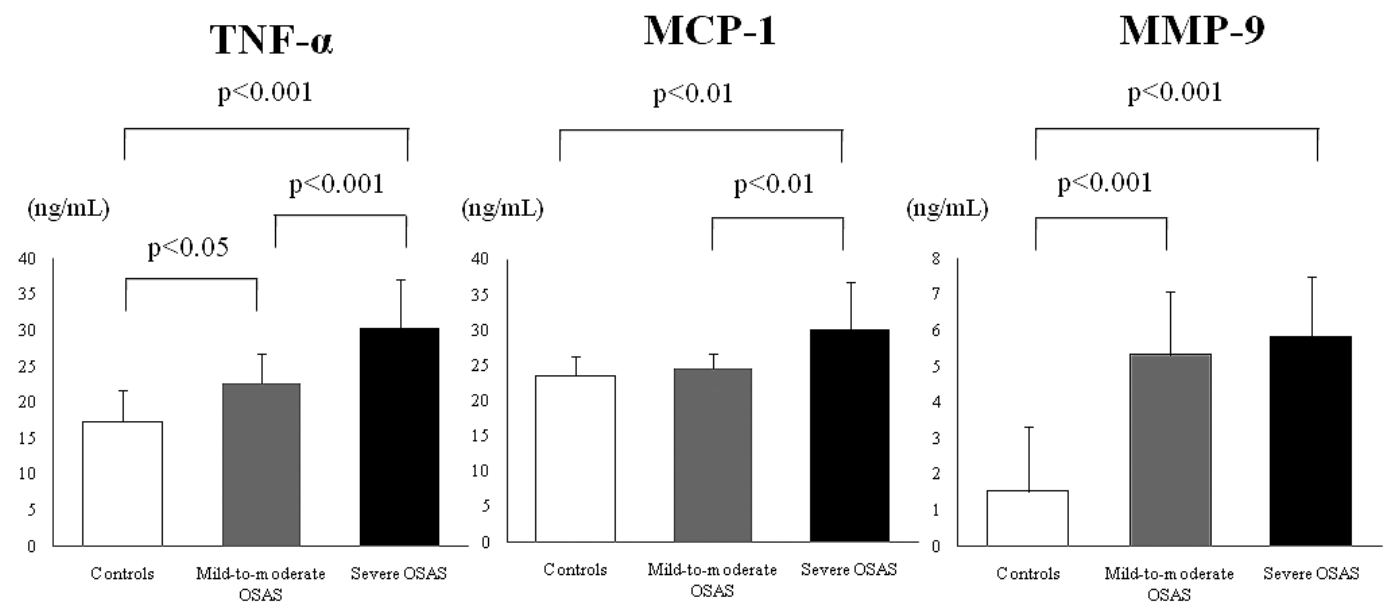

Figure 6. Production of TNF- $\alpha$, MCP-1, and MMP-9 by monocytes extracted in the early morning after adjustment for age and BMI. In severe patients, the production of TNF- $\alpha$ was significantly higher in OSAS patients than in mild-to-moderate patients $(\mathbf{p}<0.001)$ and in control subjects $(\mathbf{p}<0.001)$. The production of TNF- $\alpha$ in mild-to-moderate patients was significantly higher than in control subjects $(\mathbf{p}<0.05)$. In severe patients, the production of MCP-1 was significantly higher than in mild-to-moderate patients $(p<0.01)$ and control subjects $(p<0.01)$. In severe patients, the production of MMP-9 was significantly higher than in control subjects $(\mathbf{p}<0.001)$. The production of MMP-9 in mild-to-moderate patients was significantly higher than in control subjects $(\mathbf{p}<0.001)$.

Systemic inflammation is increasingly being recognized as a risk factor for a number of different complications including atherosclrosis (23), and it is a well-established factor in the pathogenesis of cardiovascular disease (24). With regard to the relevance of the association of cardiovascular diseases and OSAS, various pro-inflammatory cytokines, including TNF- $\alpha$, IL- 6 and adhesion molecules, induce monocyte migration into endothelial cells and subendothelial spaces. After this process, monocytes become foam cells and contribute to the progression of atherosclerosis (3). Atherosclerosis is associated with increased levels of inflammatory markers including high sensitivity $\mathrm{C}$ reactive protein, IL-6, TNF- $\alpha$, P-selectin, and homocysteine (25). Although there have been several studies on the relationship between OSAS and TNF- $\alpha$ (16-18), MCP-1 (19, 20), and MMP-9 (21), few studies have discussed the changes of these mediators before and after nocturnal hypoxic stress.

Entzian et al (26) showed that the circadian rhythm of TNF- $\alpha$ release was significantly disturbed in OSAS patients; nocturnal physiologic peaks almost disappeared and an additional daytime peak developed. In another study, circulating levels of TNF- $\alpha$ and IL- 6 were significantly elevated after the first significant apnea (27).

We demonstrated that in severe OSAS, the production of TNF- $\alpha$, MCP-1 and MMP-9 by monocytes was significantly elevated after sleep in the early morning, and all three were decreased after long-term CPAP treatment. In addition, the production of TNF- $\alpha$ by monocytes was significantly correlated with the severity of OSAS. These findings suggest that the production of TNF- $\alpha$, MCP-1 and MMP-9 by monocytes is attributed to OSAS-induced hypoxic stress.

Recently, Ryan et al (28) demonstrated that in vitro, intermittent hypoxia selectively activates nuclear factor kappaB
(NF-kappaB), a key transcription factor in chronic inflammatory diseases $(29,30)$, wheras the adaptive regulator, hypoxia-inducible factor 1 alpha, was not activated. They demonstrated a significant relationship between NF-kappaBdependent gene, TNF- $\alpha$ and sleep-related oxygen desatuation (31). In addition, we have already reported that NFkappaB activation is observed in OSAS, and it occurs in association with the facilitation of TNF- $\alpha$ production (32). It is reasonable to postulate that NF kappaB, which has been found in atherosclerotic but not in normal vessels (30), plays a pivotal role in the link between OSAS and cardiovascular disease. Blocking the NF-kappaB activation suppresses TNF- $\alpha$-induced MMP-9 expression (33) and MCP-1 expression (34) in vascular smooth muscle cells. Tsai et al (35) demonstrated that cilostazol decreases MCP-1 in LPSstimulated monocytic THP-1 cells via the NF-kappaB pathway. Lai et al (36) demonstrated that LPS induces production of MMP-9 by monocytes through the NF-kappaB pathway. These findings led us to surmise that NF-kappaB activation facilitates the production of TNF- $\alpha$, MCP-1 and MMP-9 by monocytes in OSAS, which in turn may contribute to the development of atherosclerosis.

Minoguchi et al (18) demonstrated that the spontaneous production of TNF- $\alpha$ by monocytes is elevated in patients with OSAS. In the present study, monocyte production of TNF- $\alpha$, MCP-1 and MMP-9 was evaluated under LPS stimulation. We previously demonstrated that activation of NF-kappaB is associated with TNF- $\alpha$ production by monocytes (32). It was reported that Toll-like receptor 4 (TLR4) serves as the main mediator of response to LPS $(37,38)$. LPS signaling through TLR4 results in activation of NFkappaB and subsequent signaling events (39) and may enhance the production of TNF- $\alpha$, MCP-1, and MMP-9 by 
monocytes.

Dyugovskaya et al (40) demonstrated that monocytes from OSAS patients bind more actively to cultured endothelial cells than do monocytes from control subjects, and treatment with CPAP attenuates this monocyte binding activity. We demonstrated that in severe OSAS, the production of inflammatory mediators by monocytes was significantly elevated after sleep in the early morning, and that it was decreased after long-term CPAP treatment. Activation of monocytes and elaboration of inflammatory mediators could play a role in the pathogenesis of OSAS (41), and CPAP treatment could play an important role to prevent atherosclerosis in OSAS.

In the present study, the production of inflammatory mediators before sleep did not indicate significant differences between subgroups of OSAS and control subjects. In severe OSAS patients, the production of these mediators was elevated after sleep, which was revealed to be significantly more prominent than in mild-to-moderate patients and control subjects. We speculate that this repetitive change of the production of inflammatory mediators is important from the viewpoint of pathogenesis of atherosclerosis in OSAS.

There are some possible limitations to the present study. First, BMI and age in severe OSAS patients were higher than those of control subjects in this study. Although we cannot completely exclude the influence of BMI, age and other factors in severe OSAS, the production of inflammatory mediators is elevated after sleep in the early morning, and is reduced after long-term CPAP treatment without a change in body weight.

To re-evaluate these issues, we analyzed the production of inflammatory mediators after adjustment for age and BMI, resulting in the observation that the productions of TNF- $\alpha$, MCP-1 and MMP-9 after sleep were also significantly higher in severe OSAS patients. These findings suggest that differences in obesity and age are not major determinants in these issues.

Second, OSAS is associated with numerous confounding factors such as hypercapnea sleep fragmentation, mechanical effect, arousal effect, and sympathetic overactivity. In OSAS patients, the TNF- $\alpha$ production after sleep was significantly correlated with AHI, ODI and \% time in $\mathrm{SpO}_{2}<90 \%$, and it was inversely correlated with the lowest $\mathrm{SpO}_{2}$. Furthermore, the production of TNF- $\alpha$, MCP-1, and MMP-9 were decreased after long-term CPAP treatment. It is suggested that nocturnal hypoxic stress is one of the primary causes of the augmented production of inflammatory mediators by monocytes. Further in vitro studies are necessary to prove an association between these factors.

In conclusion, OSAS-induced hypoxic stress may contribute to the development of atherosclerosis via the activation of inflammatory mediators produced by monocytes/macrophages. Furthermore, our results suggest that CPAP treatment has the potential to prevent the development of atherosclerosis by attenuating the inflammatory process.

\section{Acknowledgement}

This study was partly supported by a grant to the Respiratory Failure Research Group from the Ministry of Health, Labour and Welfare, Japan, and by a Grant-in-Aid for Scientific Research (B) (19390226) from the Ministry of Education, Science, Sports and Culture, Japan.

\section{References}

1. Lattimore JD, Celermajer DS, Wilcox I. Obstructive sleep apnea and cardiovascular disease. J Am Coll Cardiol 41: 1429-1437, 2003.

2. Peker Y, Hender J, Norum J, Kraiczi H, Carlson J. Increased incidence of cardiovascular disease in middle-aged men with obstructive sleep apnea: a 7-year follow up. Am J Respir Crit Care Med 166: 159-165, 2002.

3. Libby P, Ridker PM, Maseri A. Inflammation and atherosclerosis. Circulation 105: 1135-1143, 2002.

4. Glass CK, Witztum JL. Atherosclerosis: the road ahead. Cell 104: 503-516, 2001.

5. Tedgui A, Mallat Z. Cytokines in atherosclerosis: pathogenic and regulatory pathways. Physiol Rev 86: 515-581, 2006.

6. Cesari M, Penninx BW, Newman AB, et al. Inflammatory markers and onset of cardiovascular events: results from the Health $\mathrm{ABC}$ study. Circulation 108: 2317-2322, 2003.

7. Rollins BJ. Chemokines. Blood 90: 909-928, 1997.

8. Aukrust $P$, Berge RK, Ueland $T$, et al. Interaction between chemokines and oxidative stress: possible pathogenic role in acute coronary syndromes. J Am Coll Cardiol 37: 485-491, 2001.

9. Matumori A, Furukawa Y, Hashimoto T, et al. Plasma levels of the monocyte chemotactic and activating factor/monocyte chemoattractant protein-1 are elevated in patients with acute myocardial infarction. J Mol Cell Cardiol 29: 419-423, 1997.

10. Dollery CM, McEwan JR, Henney AM. Matrix metalloproteinases and cardiovascular disease. Circ Res 77: 863-868, 1995.
11. Sundstrom J, Vasan RS. Circulating biomarkers of extracellular matrix remodeling and risk of atherosclerotic events. Curr Opin Lipidol 17: 45-53, 2006.

12. Newby AC. Dual role of matrix metalloproteinases (matrixins) in intimal thickening and atherosclerotic plaque rupture. Physiol Rev 85: 1-31, 2005.

13. Sundstrom J, Evans JC, Benjamin EJ, et al. Relations of plasma matrix metalloproteinase-9 to clinical cardiovascular risk factors and echocardiographic left ventricular measures: the Framingham Heart Study. Circulation 109: 2850-2856, 2004.

14. Inokubo $Y$, Hanada $H$, Ishizaka $H$, Fukushi $T$, Kamada $T$, Okumura K. Plasma levels of matrix metalloproteinase-9 and tissue inhibitor of metalloproteinase-1 are increased in the coronary circulation in patients with acute coronary syndrome. Am Heart J 141: 211-217, 2001.

15. Galis ZS, Sukhova GK, Lark MW, Libby P. Increased expression of matrix metalloproteinases and matrix degrading activity in vulnerable regions human atherosclerotic plaques. J Clin Invest $\mathbf{9 4}$ 2493-2503, 1994.

16. Vgontzas AN, Papanicolaou DA, Bixler EO, Kales A, Tyson K, Chrousos GP. Elevation of plasma cytokines in disorders of excessive daytime sleepiness: role of sleep disturbance and obesity. J Clin Endocrinol Metab 82: 1313-1316, 1997.

17. Ciftci TU, Kokturk O, Bukan N, Bilgihan A. The relationship between serum cytokine levels with obesity and obstructive sleep apnea syndrome. Cytokine 28: 87-91, 2004. 
18. Minoguchi K, Tazaki T, Yokoe T, et al. Elevated production of tumor necrosis factor- $\alpha$ by monocytes in patients with obstructive sleep apnea syndrome. Chest 126: 1473-1479, 2004.

19. Ohga E, Tomita T, Wada H, Yamamoto H, Nagase T, Ouchi Y. Effects of obstructive sleep apnea on circulating ICAM-1, IL-8, and MCP-1. J Appl Physiol 94: 179-184, 2003.

20. Hayashi M, Fujimoto K, Urushibata K, Takamizawa A, Kinoshita O, Kubo K. Hypoxia-sensitive molecules may modulate the development of atherosclerosis in sleep apnoea syndrome. Respirology 11: 24-31, 2006.

21. Tazaki T, Minoguchi K, Yokoe T, et al. Increased levels and activity of matrix metalloproteinase-9 in obstructive sleep apnea syndrome. Am J Respir Crit Care Med 170: 1354-1359, 2004.

22. Havlir DV, Ellner JJ, Chervenak KA, Boom WH. Selective expansion of human gamma delta $\mathrm{T}$ cells by monocytes infected with live Mycobacterium tuberculosis. J Clin Invest 87: 729-733, 1991.

23. Ross R. Atherosclerosis-an inflammatory disease. N Engl J Med 340: 115-126, 1999.

24. Hansson GK. Inflammation, atherosclerosis, and coronary artery disease. N Engl J Med 352: 1685-1695, 2005.

25. Williams A, Scharf SM. Obstructive sleep apnea, cardiovascular disease, and inflammation-is NFKB the key? Sleep Breath 11: 6976, 2007.

26. Entzian P, Linnemann K, Schlaak M, Zabel P. Obstructive sleep apnea syndrome and circadian rhythms of hormones and cytokines. Am J Respir Crit Care Med 153: 1080-1086, 1996.

27. Alberti A, Sarchielli P, Gallinella E, et al. Plasma cytokine levels in patients with obstructive sleep apnea syndrome: a preliminary study. J Sleep Res 12: 305-311, 2003.

28. Ryan S, Taylor CT, McNicholas WT. Selective activation of inflammatory pathways by intermittent hypoxia in obstructive sleep apnea syndrome. Circulation 112: 2660-2667, 2005.

29. Barnes PJ, Karin M. Nuclear factor- $\kappa B$ : a pivotal transcription factor in chronic inflammatory diseases. N Engl J Med 336: 10661071, 1997.

30. Monaco C, Paleolog E. Nuclear factor $\kappa B$ : a potential therapeutic target in atherosclerosis and thrombosis. Cardiovasc Res 61: 671682, 2004.

31. Ryan S, Taylor CT, McNicholas WT. Predictors of elevated nuclear factor-KB-dependent genes in obstructive sleep apnea syn- drome. Am J Respir Crit Care Med 174: 824-830, 2006.

32. Yamauchi M, Tamaki S, Tomoda K, et al. Evidence for activation of nuclear factor kappaB in obstructive sleep apnea. Sleep Breath 10: 189-193, 2006.

33. Lee SO, Jeong YJ, Yu MH, et al. Wogonin suppresses TNF- $\alpha-$ induced MMP-9 expression by blocking the NF- $\mathrm{KB}$ activation via MAPK signaling pathways in human aortic smooth muscle cells. Biochem Biophys Res Commun 351: 118-125, 2006.

34. Lopez-Franco O, Hernandez-Vargas P, Ortiz-Munoz G, et al. Parthenolide modulates the NF- $\mathrm{BB}$-mediated inflammatory responses in experimental atherosclerosis. Arterioscler Thromb Vasc Biol 26: 1864-1870, 2006.

35. Tsai CS, Lin FY, Chen YH, et al. Cilostazol attenuates MCP-1 and MMP-9 expression in vivo in LPS-administrated balloninjured rabbit aorta and in vitro in LPS-treated monocytic THP-1 cells. J Cell Biochem 103: 54-66, 2008.

36. Lai WC, Zhou M, Shankavaram U, Peng G, Wahl LM. Differential regulation of lipopolysaccaride-induced monocyte matrix mettalopreoteinase (MMP)-1 and MMP-9 by p38 and extracellular signal-regulated kinase $1 / 2$ mitogen-activted protein kinases. J Immunol 170: 6244-6249, 2003.

37. Poltrak A, He X, Smirnova I, et al. Defective LPS signaling in $\mathrm{C} 3 \mathrm{H} / \mathrm{HeJ}$ and $\mathrm{C} 57 \mathrm{BL} / 10 \mathrm{ScCr}$ mice: mutations in Tlr4 gene. Science 282: 2085-2088, 1998.

38. Hoshino K, Takeuchi O, Kawai T, et al. Cutting edge: Toll-like receptor 4 (TLR4)-deficient mice are hyporesponsive to lipopolysaccharide: evidence for TLR4 as the Lps gene product. J Immunol 162: 3749-3752, 1999.

39. Yang H, Young DW, Gusovsky F, Chow JC. Cellular events mediated by lipopolysaccharide-stimulated toll-like receptor 4. MD-2 is required for activation of mitogen-activated protein kinases and Elk-1. J Biol Chem 275: 20861-20866, 2000.

40. Dyugovskaya L, Lavie P, Lavie L. Increased adhesion molecules expression and production of reactive oxygen species in leukocytes of sleep apnea patients. Am J Respir Crit Care Med 165: 934-939, 2002.

41. Hatipoğlu U, Rubinstein I. Inflammation and obstructive sleep apnea syndrome pathogenesis: a working hypothesis. Respiration 70: 665-671, 2003.

(C) 2009 The Japanese Society of Internal Medicine

http://www.naika.or.jp/imindex.html 